\section{Repensar-se, reescrever-se: das possibilidades de escritura da pesquisa em artes da cena na academia}

Rethinking, rewriting yourself: the possibilities of scripting research on scenic arts in academy

Luciane de Campos Olendzki ${ }^{1}$

RESUMO

Este artigo busca refletir sobre formas de escrever teses e dissertações na academia, como sendo correlatas com formas de pensar, conceber e produzir conhecimento. Desse modo, questiona e busca possibilidades de formas de escritura da pesquisa em artes da cena que possam ter maior correspondência com conteúdos, materialidades, processos e modos de expressão da área, tais como, o jogo, a fabulação e a performatividade. Para tal, partimos de estudos sobre a performatividade da linguagem (Austin), a crítica literária (Barthes), a filosofia (Nietzsche e Deleuze), abordando o processo de escritura da dissertação da autora.

Palavras-chave: Escrita performativa. Escritura de jogo. Escrita acadêmica.

\section{ABSTRACT}

This article aims at considering ways of writing theses and dissertations in the academy, as being correlated with ways of thinking, conceiving and producing knowledge. Thus, it questions and searches for possibilities of forms of research writing in scene arts which may have a greater correspondence with contents, materialities, processes and ways of expression of the area, such as the play, the fabulation and the performativity. For this, we started from studies on performativity of language (Austin), literary criticism (Barthes), philosophy (Nietzsche and Deleuze), approaching the author's dissertation writing process. Keywords: Performative writing. Play writing. Academic writing.
Doutoranda em Artes da Cena pela Universidade Estadual de Campinas. ORCID: http://orcid.org/ 0000-0002-4146-4456. Contato:

luquerubim@hotmail.com 


\section{Escritura e literatura}

Para desenvolver algumas reflexões sobre possíveis formas de escritura de teses e dissertações no campo da pesquisa em artes na academia, neste artigo, parto especialmente da abordagem e da análise de alguns elementos da minha dissertação de mestrado "Palhaçar: máscaras em uma patética-poética por rir" (OLENDZKI, 2009). Tal dissertação se situa em uma zona fronteiriça de produção e tessituras entre o teatro, a filosofia e a literatura, com embasamento teórico, conceitual e metodológico fundamentado nas perspectivas pós-estruturalistas, especificamente nas produções filosóficas de Gilles Deleuze e Friedrich Nietzsche.

A dissertação tem como forma de expressão uma escritura poética e literária, que se desenvolve como uma espécie de narrativa performativa e dramatizadora, ou ainda, uma dramatização fabuladora e filosófica. Investiu-se no exercício e na produção de uma escritura performativa ou que performatiza à medida que escreve, pensa e compõe. Escritura enquanto forma de expressão (não informativa ou da ordem de um discurso linear e descritivo) que opera com um pensamento em ação (que dramatiza) ou que só consegue pensar se for posto em drama (ação) pela escrita. Escritura impulsionada por afetos, dramas e imagens do pensamento, articulados com experiências artísticas e de vida, estudos e leituras pertinentes à pesquisa e à criação. Uma escritura que se desenvolve e discorre por jogo, experimentação e composição com os conteúdos teóricos e práticos da pesquisa. Através da escritura, pôr em movimento a fabulação e as conjunções que propiciam a possibilidade de pensar e criar sentidos múltiplos sobre um tema e problemática de pesquisa.

O plano de excursão da dissertação é rizomático, não desenvolve um evolucionismo historiográfico da arte do palhaço, nem instauração de origem ou de filiação entre tipos e máscaras cômicas. Para além da fixação da imagem e do conceito de palhaço, buscou-se percorrer as linhas de correlação e dupla captura entre os diferentes tipos cômicos que proliferam e constituem séries diferenciais da genealogia da palhaçaria. Desse modo, apresenta-se passagens e jogos pelos territórios da palhaçaria com seus distintos tipos genealógicos, traçando um plano topológico, trans-histórico e anacrônico de informação, composição e pensamento.

Na dissertação, tipos e máscaras da genealogia e historiografia da palhaçaria operam como personagens conceituais e intercessores para o movimento do pensamento, dramatizam os conceitos filosóficos e o próprio conhecimento da palhaçaria, operando como agentes de enunciação. Palhaços e tipos cômicos, para além de 
suas concreções e existências empíricas e históricas, atuam como potências intempestivas, enquanto personagens conceituais e filosóficas, ou seja, como "presenças intrínsecas ao pensamento, uma condição de possibilidade do próprio pensamento" (DELEUZE; GUATTARI, 2000, p. 9). Nesse procedimento de escrever-pensar-criar os planos da filosofia, da literatura e das artes cênicas tornaram-se indissociáveis na produção da pesquisa.

Os conceitos filosóficos são brincados, atuados, performados e operacionalizados no texto, sem ser explicados, em alianças e problematizações com modos da arte da palhaçaria. Deleuze demanda a "mostração pura", a imitação, a ruptura e a antropofagia em relação aos conteúdos que em articulação movimentam a produção textual e o pensamento, ao invés da explicação pautada em regime de significâncias e na chave "essência-exemplo":

A cada vez que nos interroga sobre uma significação, respondemos por uma designação, uma mostração puras. E para persuadir o espectador de que não se trata de simples "exemplo" e que o problema de Platão está mal colocado, imitaremos aquilo que designamos, nós o mimetizaremos, ou então poderemos comê-lo ou quebrar aquilo que mostramos. [...] E isso tanto mais rápido e tanto melhor que não há e não deve haver semelhança entre aquilo que se mostra e o que nos pediam: somente uma relação de dentes de serra, que recusa a falsa dualidade platônica essência-exemplo (DELEUZE, 2003, p. 138).

Conceitos e noções filosóficas são postos em ação ou dramatizados em cenas de escritura, desdobrando um drama de imagens e ficções atuados por personagens conceituais em uma escritura performativa que impele o exercício do pensamento e da produção textual em fabulação. Uma escritura que põe em "imagin-ação" os conteúdos, os conceitos e a produção de conhecimento. Como fazer, como pensar, como escrever em teatro e palhaçaria? Pôr em ação uma escritura de "mîse-en-scène, mîse-en-page" (SALOMÃO, 2000).

$\mathrm{Na}$ "Aula" pronunciada em of de janeiro de 1977 no Colégio de França, Barthes discorre sobre literatura e escritura:

Entendo por literatura não um corpo ou uma sequência de obras, nem mesmo um setor de comércio ou de ensino, mas o grafo complexo das pegadas de uma prática: a prática de escrever. Nela viso, portanto, essencialmente o texto, isto é, o tecido dos significantes que constitui a obra, porque o texto é o próprio aflorar da língua, e porque é no interior da língua que a língua deve ser combatida, desviada: não pela mensagem de que ela é o instrumento, mas pelo jogo de palavras de que ela é o teatro. Posso portanto dizer, indiferentemente: literatura, escritura ou texto (BARTHES, 1989, p. 17). 
Nesse sentido, a prática de escrever visa o texto, uma escritura que é literatura, meio e fim de um jogo combativo e teatral dentro e pela linguagem, gerando um objeto literário - seja este um poema, um romance, uma dissertação ou uma tese. Em "A Preparação do Romance I" (na Aula de 09/12/1978) Barthes (2005a) coloca que a escritura literária opõe-se à escrita da ciência, pois envolve uma verdadeira prática do desejo (querer-escrever) que contempla uma erótica do prazer do texto. Prática de querer-escrever que aporta uma força fantasística que põe em marcha a própria escritura, permitindo novas partidas e direções.

Exerci a prática de escrever desejando textos de escritura, buscando prazer e jogo no texto e na produção de sentidos. Através de procedimentos experimentais permiti que a fantasia e a própria prática de escrever apontasse e efetivasse novas direções para formas de expressão em escritura e literatura, em jogo com conteúdos da palhaçaria e da filosofia.

Uma escritura que experimenta não se limitar ao informativo, ao explicativo, aos preceitos e às ordenações pautados na lógica, nos modelos de estruturação e organização do discurso e do conhecimento científicos e na linearidade da razão. O que não quer dizer que através do jogo, da performatividade, da dramatização e da fabulação no procedimento de escrever e na forma de escritura, não se possa informar e explicar, também com clareza e rigor científico.

Segundo Perrone-Moisés (2005), Barthes coloca que a produção de escritura permitiria distinguir a escrita dos escritores $\mathrm{da}$ dos escreventes. Os escreventes (écrivants) realizam uma escrita transitiva, portadora de mensagens e de orientações. Os escritores (écrivains) escrevem intransitivamente, ou seja, sem qualquer adequação a nenhum referente, mas como processo da sua própria organização em relação à linguagem, em que o estilo se faz por transitoriedade constante, não sendo um mero revestimento formal. $\mathrm{O}$ estilo da escritura estaria relacionado à fusão de pensamento e impulso inconsciente, através de uma enunciação consciente.

Ao invés de capítulos, a dissertação é composta por cenas de escritura, que se apresentam em distintas variações, tais como, fragmentos, diálogos, poesias, contos, narrativas e ensaios. Cenas de escritura que não foram escritas para serem encenadas, não contam uma história, mas várias, não possuem unidade de tempo, lugar e ação. As cenas de escritura dramatizam, mas não são dramáticas. Cenas que se dão em não-lugares, tempos indefinidos, com ou sem personagens. Cenas que desdobram uma dramatização filosófica, tendo como problemática ética e poética a arte do palhaço. 
Após cada cena de escritura, há o livro do ponto (espécie de notas finais), onde se desdobram outros textos, tais como: a) aforismos; b) notas explicativas - sobre conceitos filosóficos, contextualizações e dados sobre a historiografia e a arte do palhaço; c) citações de obras que ampliam ou embasam o que está posto na cena de escritura e d) referências bibliográficas. O livro do ponto faz alusão ao ponto do teatro e à sua função, enquanto recitador informativo e guia no subterrâneo das cenas de escritura.

Por outro lado, a possibilidade de uma filosofia literária ou de um drama filosófico é inaugurada por Nietzsche, especialmente em "Assim Falou Zaratustra" (1885), o que segundo Deleuze (1976), implica a assimilação do teatro pelo pensamento, ou seja, a reformulação do pensamento como experiência e como movimento, o que demanda uma reformulação da linguagem, isto é, dos modos correspondentes de expressão.

\section{Escrita performativa}

Cada vez mais é recorrente ouvirmos falar sobre a escrita performativa como possibilidade de escrita de dissertações e teses na pesquisa em artes da cena, mas pouco ou quase nada se explana de forma clara e consistente sobre do que se trata tal "escrita performativa". Sendo assim, a grosso modo, associa-se a escrita performativa com todo e qualquer formato que não se enquadre nos moldes padrões de escrita acadêmica.

Afinal, do que se trata quando nos referimos ou qualificamos uma escrita como performativa? O que este termo "performativo" significa e implica enquanto distinção e nominação de uma forma de escrita? Quais são os elementos, as características, especificidades e diferenciais de uma escrita performativa? Tais questões podem balizar o desenvolvimento de um estudo e análise sobre a escrita performativa, especialmente no âmbito da pesquisa em artes da cena na academia.

As teses e dissertações acadêmicas são objetos literários (de escrita e leitura), suportes que ganham corpo, existência e sentido via a escrita. Sendo a escrita a expressão legitimada e convencionada para a comunicação e partilha da pesquisa acadêmica. Portanto, enfocaremos a performatividade no campo da linguagem, por se tratar da abordagem de uma "escrita" performativa, limitando-se a um estudo inicial e parcial, que não pretende dar conta do tema em sua completude e complexidade. Deste modo, busca-se aportar algumas perspectivas e concepções que podem dar suporte e consistência aos questionamentos acima referidos, servindo às possíveis articulações e análises em torno de 
considerações sobre a escrita performativa na pesquisa acadêmica em artes da cena.

A noção de performativo na linguagem foi desenvolvida por John Langshaw Austin, entre 1940-50, filósofo da escola de Oxford, que introduziu os conceitos de "performativo", "ilocucionário" e de "ato de fala" na filosofia analítica e na linguística. Ottoni (1998) propõe uma "visão performativa" da linguagem, através da análise e do estudo das obras principais de Austin em torno da performatividade da fala, e que neste artigo serão os referencias para a abordagem das principais concepções desse autor.

Segundo Austin (1975), há circunstâncias de uso da linguagem nas quais não descrevemos a ação, mas a praticamos. O enunciado performativo realiza uma ação, independente das propriedades verdadeiro ou falso. O performativo passa estar ligado a um contexto, e ao invés do verdadeiro ou falso, há os parâmetros de avaliação: se foi "feliz" - caso a ação pretendida tenha sido realizada, ou "infeliz" - se a ação pretendida não foi realizada. Austin desdobra o ato de fala em três atos simultâneos e correlacionados, que de forma esquemática são: a) ato locucionário (sentido) - fala, articulação entre a sintaxe e a semântica, lugar em que se dá a significação; b) ato ilocucionário (força) - ato de realização de uma ação através de um enunciado, possibilita fazer a distinção entre o dizer e o dito; c) ato perlocucionário (efeito) - ato que produz efeito sobre o interlocutor. $O$ ato locucionário é a realização de um ato de dizer algo; o ato ilocucionário é a realização de um ato ao dizer algo (força da enunciação); e o ato perlocucionário produz um efeito sobre o interlocutor. O performativo realiza uma ação através de um enunciado que é a realização de um ato de fala, o performativo é o próprio ato de realização da fala-ação.

O performativo é mobilizado não apenas por verbos performativos e sujeitos agentes (pronomes de tempos verbais), mas ele está presente mesmo nas constatações (sem verbo na voz ativa ou passiva). Com isso, também as constatações ou as afirmações "não só dizem sobre o mundo como fazem algo no mundo. Não descrevem a ação, praticam-na" (OTTONI, 1998, p. 37).

Derrida (1991) aborda a problemática do performativo a partir de Austin no texto "Assinatura Acontecimento Contexto" (1972). Dentre aportes fundamentais, Derrida avalia que Austin retirou da análise da linguagem a oposição verdade-falsidade, substituindo-a pela consideração de valor e diferença de força, também atacando a visão logocêntrica, a racionalidade da fala e o discurso enquanto universal. 
Conforme Zular (2007, p. 43), "o caráter performativo da linguagem define a própria característica da literatura na medida em que ela constrói aquilo que ela fala, isto é, na medida em que ela se constitui pelo fazer um mundo próprio que não existe senão quando de sua enunciação".

A presença e a fabricação da ficção como forma de ver e dizer o mundo, re-imaginá-lo, remodelá-lo e, portanto, também de constituí-lo, encontra suporte e consonância com os estudos de Conquergood (apud PINEAU, 2010), que deslocou paradigmas da performance artística para a perfomatividade cultural, e que segundo Pineau (2010, p. 96) possibilitou "a redefinição da performance como um paradigma, como uma metáfora exploratória, como método de pesquisa e como ativismo de justiça social". O que no campo da educação ensejou uma produção crítica que demanda a passagem de uma "pedagogia informativa" para uma "pedagogia performativa". Conquergood traz à baila a figura do trickster como importante agenciador para a escrita e a pesquisa performativas:

[...] assim que uma visão de mundo tenha sido fabricada, linhas são destacadas, categorias definidas, hierarquias erigidas, um personagem arquetípico aparece, o trickster. Movendo-se no rompimento das normas, na violação dos tabus, o trickster vira tudo de cabeça para baixo. Ao jogar com a ordem social, desalojando certezas, ele acaba por intensificar a consciência da vulnerabilidade de nossas instituições (CONQUERGOOD, apud PINEAU, 2010, p. 101).

Conquegoord exalta alguns elementos significativos para a o exercício da performatividade na produção de uma pesquisa, tais como: improvisação, inovação, experimentação, contextualização, reflexão, agitação, ironia, paródia, sarro, cômico e carnavalização. Um princípio crucial relacionado à pesquisa performativa, defendido por Conquegoord, é a mudança de foco do produto para o processo ou para a produtividade.

Dentro de uma perspectiva da visão performativa direcionada à literatura, Zular (2007) aponta que há ao menos duas possibilidades de inter-relação entre as práticas de escrita e sua construção formal: 1) uma visada mais tradicional ligada à passagem da produção escrita à forma e 2) outra que escancara o próprio processo enquanto forma. No segundo caso, a performatividade do processo pode se configurar formalmente, em que o performativo torna-se uma maneira particular de pensar a forma, pelo o que ela faz. Sendo assim, os próprios procedimentos do ato de escrever (performatividade do processo) passam a constituir formas de escrever e formas de pensar. 
Escritura de Jogo

Se pois me interrogam; se se inquietam (como acontece, e às vezes muito vivamente) acerca do que eu "quis dizer", respondo que eu não quis dizer, mas quis fazer e que foi a intenção de fazer que quis o que eu disse... Paul Valéry

Na dissertação "Palhaçar: máscaras em uma patética-poética por rir" (2009), o processo de escrever se agenciava como jogo, como experimentação e composição lúdicas (de brincadeira e combate) para lidar com conteúdos e questões, fazer alianças entre matérias diversas e heterogêneas, como a palhaçaria e a filosofia.

Busca de uma escritura to perform. Força fantasística. Prática de querer-escrever. Uma escritura atuada. Palavra-ação. Escrituraação. Contar uma história sem fim nem moral. Ficcionalizar o conhecimento. Inventar e questionar verdades. Discorrer bio-grafias. Permitir-se a escritura-rasura. Em riscos. Por linhas de fabulação. Escritura enquanto ato de criação. Ars escrita. Escritura mascarada em espaço de jogo. Quando não sei falar e algo precisa falar. Aprendi a falar escrevendo com o corpo. Jogando uma máscara. Portanto, as palavras querem brincar, construir um corpo literário, fazer-se cena, sensações, dramas de imagens e pensamentos. Máquina de escritura operando nos intervalos, nos blecautes, de dentro da própria escritura, escrevendo tese ou dissertação.

Escritura como jogo - implicando jogo com a linguagem e o arranjo entre conteúdos diversos. Jogo de pensamento, jogo polissêmico de vozes, referências e sentidos. Instigante e difícil tarefa, pois a própria linguagem já é um sistema de convenções e códigos, que é forma de poder, de direcionamento de modo de pensar, aportando elementos específicos e marcas da cultura. Faz-se necessário sagazes tricksters, malabaristas da linguagem para compor jogos de linguagem, de escritura e de pensamento, que também permitam e convidem o leitor a jogar junto.

A atitude lúdica ou de jogo no ato de escrever era o que geralmente fazia proceder a escritura da dissertação, ou mesmo, a passagem de textos de escrevência às cenas de escritura. A partir daí, realizava-se inúmeras revisões e re-escrituras, cortes, encaixes e articulações. Textos de caráter informativo, com revisão bibliográfica e explicações acabavam sendo cortados das cenas de escritura, pois traziam morosidade, bloqueio de estilo, didatismo, ainda que contivessem informações significativas. Para tentar sanar tais questões, criei o "livro do ponto" - espécie de notas finais, abaixo de cada cena de escritura. O livro ponto é o lugar do escriba. Visto que, também como escriba que pude exercitar a escritura 
- copiando, anotando, coletando, arquivando e "recitando". O ponto torna-se a base e o guardião do conhecimento das fontes da pesquisa, apontando as referências, resguardando os escritos de autores que tenham sofrido alterações na cena de escritura. As citações de autores reditas por personagens conceituais, algumas vezes, sofriam alterações parciais ou mesmo inversões de sentido - o que era esclarecido no livro do ponto. Como parte do jogo, eram feitas alterações, substituições e inversões em função dos personagens e da cena de escritura, ou seja, conforme quem fala, como age ou o que age. Afinal, como brinca Nietzsche (2005b, p. 174), com "um corcunda pode-se falar perfeitamente de um modo torto!".

$\mathrm{O}$ ato de escrever se agenciava como jogo, forma criativa de tratar um assunto ou questão, de fazer alianças e se surpreender no manuseio de conteúdos e referenciais prático-teóricos que fundamentaram e balizaram a pesquisa. O próprio ato de escrever a dissertação se tornava ele mesmo performativo, ou seja, como processo que implicava e gerava a forma de escritura e os gêneros (conto, poesia, ensaio, drama), com diferentes nuances do fantástico e do onírico. O escrever em jogo é que fazia tal ou qual modo de escritura, gerando, conduzindo e articulando intencionalidades e formas de expressão.

Quem punha o pensamento e a escritura em ação não era um "eu", mas personagens conceituais (DELEUZE; GUATTARI, 2000), em um jogo de máscaras. Realizava-se uma atuação em escritura, com as figuras da genealogia da palhaçaria que, então, movimentavam o pensamento e faziam proceder as formas de escritura. Por vezes, os próprios autores de referência tornavam-se personagens conceituais nas cenas de escritura, fazendo suas re-citações. Sucediam-se conversações diretas com os autores de referência da pesquisa, postos como personagens em cenas de escritura, até mesmo em pleno picadeiro circense. Assim, desdobrava-se um jogo com as obras lidas de forma ativa, criativa, lúdica e antropofágica, sem se deter na "informatividade" e investindo na performatividade.

Ora adotava o procedimento de escrever atuando como bufões, desdobrando ambiguidades de sentidos, jogo de palavras, questionamentos ferinos sobre o riso, a presença do diferente e o poder. Ora escrevia com a máscara do Dottore da Commedia Dell'Arte em um banquete (paródia de "O Banquete" de Platão), em que um grupo de Dottores destroçam com ironia e absurdo os sentidos etimológicos da palavra "clown" e "palhaço", questionando qualquer fundamento de origem ou essência do palhaço. Também, escrevi como uma criança que vai ao circo pela primeira vez, exci- 
tada com o encontro com o palhaço e, no entanto, mal sabe falar. Escrevi como se estivesse sonhando e também utilizando sonhos atravessados por palhaços e seus arquétipos. E ainda, escrevi como palhaça, com olhar torpe e fantasioso para poetizar e brincar sobre o que se escreve, como se escreve, vive e fabula uma dissertação.

Algumas cenas de escritura foram escritas para serem lidas em voz alta, por exemplo, com jogos de dislalias e repetição de consoantes para tornar presente a embriaguez, como estado referido ao palhaço e à máscara que porta do nariz vermelho (nariz de bêbado), com seus tropeços e fala torpe. Também, escrevia a partir de ações, acompanhadas por sensações, por exemplo: como quem cai, se perde, sonha, involui, julga.

Operar e escrever com um pensamento "como se" de teatro. Tendo como tarefa de jogo: escrever; tendo como forma de expressão: a linguagem escrita. Produzir conhecimento fabulando e ficcionalizando com os saberes para a construção composicional de texto e pensamento - postos em ação e jogo, em cenas de escritura.

Fabulação, alteridade e performatividade em jogos em que personagens conceituais em cenas de escritura entrelaçam e compõem diferentes planos: experiência vivida e experiência fabulada; palhaçaria e filosofia; absurdo e lógico; razão e desrazão; informação e imaginação; fatos e invenção; infância e erudição; escritura e leitura; ética e poética. Assim, resulta um "palhaçar" em plano filosófico, uma erudição infantil e absurda, um rigor acadêmico brincado, um conhecimento imaginado, jogado e teatralizado. A própria produção de conhecimento assumindo-se como criação, como ficção, invenção, não-Verdade. A fabulação, a alteridade e a ficcionalização de e com dados do conhecimento teórico e artístico foram procedimentos de jogo e de composição para uma reflexão e escritura performativas.

Uma escritura de jogo, também performativa, que contempla a experiência e a produção de alteridade no próprio procedimento de escrever. Em que o autor se torna um bando, escreve sempre como sendo outros e usando máscaras. "Eu" torna-se um espaço de alteridade com a prática de escrever. Prática impelida por afetos e jogos provenientes de encontros e problematizações com conteúdos da palhaçaria e da filosofia. Uma escritura de dissertação que também implica uma experimentação de si em processo de criação em escrita. Como escrever, repensando-se e reescrevendo-se, sem uma experimentação de si? Entrada em territórios do desconhecido, do não-sabido e do irreconhecível em processos de escritura. Nietzsche (2005a, p. 181) com ironia questionava-se em seus cantos ditirâmbicos: " $\mathrm{Eu}$ - não sou mais eu? Mudaram a mão, o rosto, o passo? E o que sou, amigos - não sou para vocês?”. 
Os procedimentos de escritura aportaram a experiência permanente de estar à deriva no processo de pesquisa e produção da dissertação. Sem conseguir vislumbrar e controlar previamente qual seria o resultado, onde desembocaria cada texto escrito, já que era no próprio procedimento de escrever que forma-expressão-produção se configuravam.

Tal prática e metodologia de escritura e pesquisa também foram fundamentadas na perspectiva pós-estruturalista, que interferiu diretamente na forma de pesquisar-fazer-escrever a dissertação.

Nesse percurso de contato com a perspectiva pós-estruturalista, especialmente a partir das filosofias da diferença, com Nietzsche e Deleuze, sofri abalos na forma de pensamento, de concepção de mundo, de modo de proceder em relação à pesquisa, de pensar o palhaço e o próprio ato de escrever uma dissertação em pesquisa em artes na academia. Tais experiências não foram apenas prazerosas, foram essencialmente desestabilizadoras e desafiadoras gerando uma série de questionamentos, onde as certezas não paravam de escapar e desfazerem-se.

Como já foi apontado anteriormente com Conquergood, sobre o papel do trickster na pesquisa performativa, era como se o impulso brincalhão desse arquétipo, tão correlato ao palhaço, viesse não só desestabilizar os padrões enrijecidos de escrever (e pensar) uma dissertação, mas também desassossegar e pôr em questão a própria produção em jogo. Daí, surgiram embates em relação a própria produção, especialmente quando entravam em cena juízos relativos aos parâmetros legitimados e majoritários de estruturação da pesquisa acadêmica. Tais embates promoveram autoquestionamentos radicais, envolvendo revisão de paradigmas assentes na produção de pesquisa acadêmica e também de opiniões de senso comum em relação à arte do palhaço. Como coloca Conquergood (apud PINEAU, 2010, p. 101), "o impulso brincalhão do trickster promove um crítico e radical autoquestionamento que leva a um conhecimento de si mais profundo, o primeiro passo para a transformação". Nessa situação, tornava-se evidente a percepção de que a produção de pesquisa e conhecimento na universidade, e como isso é feito, diz respeito às formas de pensar, implicando não só concepções de mundo, mas ações no mundo e, principalmente, construções deste mundo.

O pós-estruturalismo deriva da filosofia e aporta questionamentos sobre o conhecimento seguro das coisas, o senso comum (a Doxa) assente e tido como dado, atentando para que não há fatos ou verdades em si, mas interpretações. Deste modo, conduz-se para uma atitude e uma produção críticas, para a realização de 
avaliações e perspectivismos que acabam por expor as fundações morais que sustentam valores correntes, enfatizando os modos de vida e os regimes de signos como construções históricas, sociais e culturais. A subjetividade é entendida como produção social. Noções e valores implicados nos modos de existência e nas relações de poder atuais e que são dados como verdades, originários e universais são questionados, tais como: a Razão, o Ser, a Verdade, o Ideal, a Origem. Com isso, podemos dizer que o efeito performativo das enunciações pós-estruturalistas é sentido e interpretado como desconstrução. O devir da história e do homem são proeminentes, em substituição do "é", se visibiliza o "vir-a-ser", o tornar-se, as fissuras e os interstícios do-que-foi e do-que-está-sendo para um por vir, aqui e agora.

No exercício do questionamento e da crítica (produtiva e propositiva), a ironia e o paradoxo são recursos utilizados pelos pós-estruturalistas na forma de pensamento e uso da linguagem. Neste contexto, a linguagem forma o mundo, não o reproduz simplesmente. Através da escritura, empreendem-se procedimentos e fazem-se presentes qualidades, tais como: contraste, emotividade, urgência, euforia, extravagância, variação, contradição, subversão, instabilidade, buracos, fissuras, quebras, descontinuidades, uso de alusões e trocadilhos, deslocamentos, omissões, aporias, jogos de linguagem, fragmentação, não-unidade, uso da metáfora, trabalho com a materialidade da linguagem, desdobramento da etimologia das palavras e de seus sentidos, uso e variação da primeira (eu) e da terceira pessoa (ele), coexistência e variação de tempos verbais no passado e no presente, etc.

Segundo Barry (2002), busca-se a produção de uma textualidade onde os signos flutuam, há disseminação, dispersão, aporia e o deslizamento de signos independente do que estes designam, com ausência de origens ou referentes fundantes, unos e identitários - o que provoca incerteza, descentramento e pluralidade de sentidos.

Escrita acadêmica?

Somente enquanto criadores podemos destruir! Nietzsche

Por que muitas vezes a escrita acadêmica pode ser tão entediante, asséptica, sem vitalismo, sem cor, sem pulsação, sem estilo, sem variação, sem humor e jogo? Por que dissertações e teses podem prescindir de uma erótica do texto, do prazer de escritura e especialmente do prazer da leitura, muitas vezes, limi- 
tando-se à "escrevência"? Quem quer saber sem sabor?

Querer-escrever uma escritura que convide ao sentir-pensar, ao prazer, ao desafio, ao não-saber, à imaginação, à sapientia. "Sapientia: nenhum poder, um pouco de saber, um pouco de sabedoria, e o máximo de sabor possível" (BARTHES, 1989, p. 45). Investir na escritura de teses e dissertações - objetos literários, com rigor composicional, conceitual, procedimental, sem perder o envolvimento estético e a erótica do texto-pensamento.

Pois afinal, o que está em jogo? Não são simplesmente formas de escrita ou escritura (poética, performativa, acadêmica, científica), nem possíveis discursos tipificados (de artista, de acadêmico, de teórico, etc.). A questão principal é o que se opera, o que se faz, o que se pensa ao se aderir, reproduzir ou experimentar determinado modo de proceder, escrever e pensar? Com qual máscara, em qual jogo? Em qual interlocução, com e para qual mundo? Com qual ação e construção de mundo? Como observa Barthes:

Sabemos que não se pode escrever diferente, salvo se se pensar diferente. Pois escrever é já organizar o mundo, é já pensar (aprender uma língua é aprender como se pensa nessa língua). É portanto inútil pedir ao outro que se reescreva, se ele não está decidido a se repensar (BARTHES, 2003, p. 202).

Os padrões de produção e escrita tidos como acadêmicos e científicos implicam valores, juízos e formas de poder, que condicionam modos de pensar e agir. Não podem ser simplesmente sustentados "como se" assim é ou assim sempre foi. Não se trata simplesmente de uma negação fortuita das formas dadas e instituídas de escrita e organização de teses e dissertações, mas do exercício crítico e criativo para abertura de procedimentos e outros formatos que permitam tornar a linguagem - a escritura - consonante e afetável pelos conteúdos que trata de formas de expressão não linguísticas, tais como temas, processos e resultados artísticos. Como movimentar sensações, afetos, sentidos sensoriais e corporais advindos da arte, também na ordem da linguagem em um formato que possa comportar tais expressões? Para Deleuze e Guattari, a Arte (2000, p. 253) - uma das três grandes formas do pensamento (além da ciência e da filosofia), "traça um plano de composição que carrega por sua vez monumentos ou sensações compostas, sob a ação de figuras estéticas".

Quais modos de composição de produções acadêmicas (tese, dissertação, artigo) podem ser correlatos com o pensar-fazer arte, para além das formas legitimadas e padronizadas? Podemos nos desvencilhar dos formatos e tipificações da pesquisa científica 
para desenvolver e incrementar modos de pesquisa em artes, sem uma relação conciliar e de legitimação fundamentada na ciência ou em outras áreas não-artísticas das humanas? Por que a forma de pesquisa em artes na academia, especialmente a produção de teses e dissertações, muitas vezes sustenta e perpetua uma relação servil e submissa aos métodos e pressupostos científicos, relacionados a produção de ciência e não de arte? A pesquisa em artes na academia precisa encontrar sua justificação, razão, defesa, legitimidade e validade fora do campo da arte? De onde parte a desvalorização e bastardia da arte como campo de conhecimento? Estamos ainda reproduzindo o pensamento socrático-platônico da valoração da Ideia, em que a arte é considerada reles cópia deturpada da natureza, sendo falsa, ilógica, demasiado carnal e material, patética (de baixas paixões), inútil, enganadora?

Como artistas-pesquisadores devemos nos atentar sobre quais formas de valoração e poder estamos (re)produzindo através dos modos de (re)produção de teses e dissertações em artes calcadas em metodologias e pressupostos científicos. Com isso, nos questionarmos sobre quais concepções de mundo engendramos ou perpetuamos? Qual lugar, forma e voz damos a arte nesse mundo (acadêmico)? É necessário (re)pensar as metodologias e epistemologias na pesquisa em artes da cena, mas fundamentalmente nos repensar como artistas-pesquisadores, implicando o que e como estamos fazendo pesquisa em artes. Com responsabilidade sobre o que estamos sendo e o que queremos enquanto artistas-pesquisadores dentro e fora da academia - uma tarefa de pesquisa e criação, de ética e de poética, envolvendo forma de produção de conhecimento e (re)criações incessantes de modos de se relacionar, ver e constituir mundos. Cabe à nós fazer e refazer, escrever e reescrever os modos de pesquisa e produção acadêmica. Principalmente, envolvendo repensar-se e reescrever-se como artistas-pesquisadores em interlocução com o mundo, engendrando possibilidades outras de ações e constituições de mundos em arte e pesquisa. 
AUSTIN, John Langshaw. How to do things with words. Cambridge, MA: Harvard University Press, 1975.

BARRY, Peter. Beggining Theory: an introduction to literaly and cultural theory. New York, NY: Manchester University Press: Palgrave Macmillan, 2002.

BARTHES, Roland. A Preparação do Romance I: da vida à obra: notas de cursos e seminários no Collège de France, 1978-1979. São Paulo: Martins Fontes, 2005a.

BARTHES, Roland. A Preparação do Romance II: a obra como vontade: notas de curso no Collège de France 1979-1980. São Paulo: Martins Fontes, 2005b.

BARTHES, Roland. Aula (pronunciada dia 7 de janeiro de 1977). São Paulo: Cultrix,1989.

BARTHES, Roland. Crítica e verdade. São Paulo: Perspectiva, 2003. DELEUZE, Gilles. Lógica do Sentido. São Paulo: Perspectiva, 2003. DELEUZE, Gilles. Nietzsche e a Filosofia. Rio de Janeiro: Rio, 1976. DELEUZE, Gilles; GUATTARI, Félix. O que é a Filosofia? São Paulo: Ed. 34, 2000.

DERRIDA, Jacques. Assinatura, acontecimento, contexto. In: Derrida, J. Margens da filosofia. São Paulo: Papirus, 1991, p. 349-373.

NIETZSCHE, Friedrich. A Gaia Ciência. São Paulo: Companhia das Letras, 2001.

NIETZSCHE, Friedrich. Além do Bem e do Mal: prelúdio a uma filosofia do futuro. São Paulo: Companhia das Letras, 2005 .

NIETZSCHE, Friedrich. Assim Falou Zaratustra. Rio de Janeiro: Civilização Brasileira, 2005b.

OLENDZKI, Luciane. Palhaçar: máscaras em uma patética-poética por rir. 2009. Sss f. Dissertação (Mestrado em Educação) Programa de Pós-Graduação em Educação, Faculdade de Educação, Universidade Federal do Rio Grande do Sul, Porto Alegre, 2009.

OTTONI, Paulo Roberto. Visão Performativa da Linguagem. Campinas, SP: Editora da UNICAMP, 1998.

PERRONE-MOISÉS, Leyla. Texto, Crítica, Escritura. São Paulo, Martins Fontes, 2005.

PINEAU, Elyse Lamm. Nos Cruzamentos Entre a Performance e a Pedagogia: uma revisão prospectiva. In: EDUCAÇÃO \& REALIDADE. Porto Alegre: UFRGS/ FACED 35(2): 89-113 maio/ago 2010. RIBEIRO, Delfim Paulo. Investigação Baseada nas Artes: caminhos de metáfora e escrita performativa. In: Performa '11 Encontros de Investigação em Performance Universidade de Aveiro, maio de 2011. 
SALOMÃO, Waly. Tarifa de Embarque. Rio de Janeiro: Rocco, 2000. ZULAR, Roberto. Uma Visão Performativa da Crítica Genética. In: Revista de Letras, São Paulo, 47 (2): 39-56, jul./dez. 2007. 